\title{
Resistencias y alternativas al desarrollo en América Latina y Caribe: Iuchas sociales contra el extractivismo*
}

\section{Enara Echart Muñoz y María del Carmen Villarreal Villamar**}

\begin{abstract}
Resumen
La represión creciente de las resistencias al modelo de desarrollo vigente hacen del mundo un lugar peligroso para los activistas. Según Naciones Unidas (2017), tres de cada cuatro asesinatos de defensores de derechos humanos ocurren en las Américas, de los cuales $41 \%$ eran contrarios a proyectos extractivistas o defendían el derecho a la tierra y a los recursos naturales de los pueblos indígenas. Partiendo de esa realidad, este artículo analiza el papel de los movimientos sociales en las disputas sobre los sentidos del desarrollo en América Latina y Caribe, con foco en las luchas contra el extractivismo. Para ello, se ha realizado un mapeamiento de estas luchas a partir de un banco de datos con 259 conflictos en torno a la minería, desarrollado por el Grupo de Relaciones Internacionales y Sur Global (GRISUL), para mostrar sus impactos en diversas dimensiones (como medio ambiente, género, territorios indígenas, desplazamientos de población, entre otros), así como los procesos de criminalización surgidos frente a los mismos. Además, mostraremos también la tendencia regional de construcción de alternativas al modelo extractivista dominante. .
\end{abstract}

\section{Palabras Clave}

Resistencia; Movimientos Sociales; Alternativas al Desarrollo; Extractivismo; América Latina y Caribe.

\section{TITLE}

Resistance and alternatives to development in Latin America and the Caribbean: social struggles against extractivism

\section{Abstract}

The growing repression of resistance to the current development model makes the world a dangerous place for activists. According to the United Nations (2017), three out of four murders of human rights defenders take place in the Americas, $41 \%$ of which were against extractive projects or defended the right to land and natural resources of indigenous peoples. Considering this reality, this article analyzes the role of social movements in the disputes around the meaning of development in Latin America and the Caribbean, with a focus on struggles against extractivism. For that, a mapping has been made from a data bank with 259 conflicts around mining, developed by the Research Group on International Relations and Global South (GRISUL), to show its impacts in various dimensions (such as environment, gender, indigenous territories, population displacement, among others), as well as the processes of criminalization that have arisen against them. In addition, we will also show the regional trend of construction of alternatives to the dominant extractivist model.

\section{KEYWORDS}

Resistance; Social Movements; Alternatives to Development; Extractivism; Latin America and the Caribbean.

\footnotetext{
* Este artículo es resultado de la investigación "Cooperación Sur-Sur y Modelos de Desarrollo en América Latina", realizada con apoyo del Programa Jovem Cientista do Nosso Estado de la Fundação de Amparo à Pesquisa do Estado do Rio de Janeiro (FAPERJ), y desarrollada con el Grupo de Investigación sobre Relaciones Internacionales y Sur Global (GRISUL) de la Universidad Federal del Estado de Rio de Janeiro (UNIRIO). Agradecemos a los/as investigadores/ as del GRISUL el trabajo de recogida y organización de los datos referentes a los conflictos por extractivismo (compilados en la cartilla Pacha: defendiendo la tierra. Extractivismo, conflictos y alternativas en América Latina, 2018), así como al Ateliê de Cartografia del Labmundo/IESP la elaboración de los mapas que ilustran este artículo.
}

** Enara ECHART MUÑOZ, Doctora en Relaciones Internacionales por la Universidad Complutense de Madrid, es profesora de la Universidad Federal del Estado de Rio de Janeiro (UNIRIO) y coordinadora del Grupo de Investigación sobre Relaciones Internacionales y Sur Global (GRISUL) y del Grupo de Trabajo de CLACSO "Cooperación Sur-Sur y Políticas de Desarrollo".

\section{María del Carmen} VILLARREAL

VILLAMAR, Doctora en Ciencia Política por la Universidad Complutense de Madrid. Actualmente realiza un postdoctorado en la Universidad Federal del Estado de Rio de Janeiro (UNIRIO) y es investigadora del Grupo de Investigación sobre Relaciones Internacionales y Sur Global (GRISUL / UNIRIO).

Recibido:

07/05/2018

Aceptado:

29/08/2018

\section{DOI:}

https://doi. org/10.15366/relacionesinternacionales2018.39.008 


\section{ntroducción}

Según la organización internacional Global Witness ${ }^{1}$, el mundo es un lugar cada vez más peligroso para activistas medioambientales, líderes comunitarios o indígenas y defensores de la tierra. La represión creciente hacia el activismo en favor de la tierra, el medioambiente, el mantenimiento de formas tradicionales de vida o la defensa de alternativas respecto al modelo de desarrollo vigente determina que estos procesos sean castigados por diversas acciones. Éstas incluyen amenazas, estigmatizaciones y violencia física que en muchos casos culminan con el asesinato de todo aquel que se atreva a alzar la voz en contra de los intereses de multinacionales, estados o grupos paramilitares interesados en explotar de forma predatoria la tierra y los recursos naturales.

En el marco del modelo de producción y acumulación extractivista, actividades como la minería o el agronegocio avanzan de forma violenta, afectando a todos los países, pero especialmente a los del Sur Global. América Latina y Caribe, por ejemplo, tienen el récord de asesinatos de líderes y activistas medioambientales como Berta Cáceres (Honduras), Iraúna Ka'apor (Brasil), Emilsen Manyoma (Colombia) o Isidro Balenegro López (México). La represión, la violencia y el silenciamiento de voces críticas al extractivismo es una constante en la región, pero su importancia crece en la medida en que se expande la frontera extractiva y aumenta, por un lado, la demanda global de productos primarios y, por otro, las acciones de actores privados o las alianzas entre estados y empresas multinacionales. Este proceso ha sido especialmente visible durante la última década, cuando se experimentó el boom del precio de las commodities y una lucha sin cuartel por territorios para el extractivismo.

En este contexto de expansión del extractivismo y de creciente criminalización de la protesta y de la resistencia ante su avance en América Latina y Caribe, cabe preguntarse: ¿cuál es el papel de los movimientos sociales? ¿De qué forma las comunidades se organizan y articulan para defender su derecho a la tierra, al agua y a una vida digna? ¿Cuáles son sus formas de contestación y resistencia al extractivismo? ¿Sus acciones se limitan a resistir el avance del extractivismo o, proponen, por el contrario, modelos alternativos de bienestar? En este escenario, partimos del presupuesto de que los movimientos sociales, con el protagonismo de campesinos, mujeres, indígenas y afrodescendientes, disputan los sentidos y las formas en los que se concibe e implementa el desarrollo ${ }^{2}$, al tiempo que cuestionan sus promesas incumplidas y su fracaso en diversas esferas, formulando alternativas de bienestar que surgen de sus necesidades, anhelos y cosmovisiones ${ }^{3}$.

Aunque las luchas y resistencias de estos colectivos son históricas, su activa participación a menudo pasa desapercibida o es vista apenas como un fenómeno local y secundario, desconociendo las interconexiones entre actores y dispositivos de poder de carácter nacional,

\footnotetext{
1 Global Witness (2017). Defensores de la tierra y del medio ambiente muertos em 2017. Disponible en: https:// www.globalwitness.org/en/blog/new-data-reveals-197-land-and-environmental-defenders-murdered-2017/ [Consultado el 5 de mayo de 2018].

2 ECHART, E. "Movimientos de mujeres y desarrollo", en CARBALLO DE LA RIVA, Marta (coord.). Género y desarrollo: cuestiones clave desde una perspectiva feminista. Madrid: IUDC-Los Libros de La Catarata, 2017, pp. 131-159.

3 BRINGEL, B. y ECHART, E. Imaginarios sobre el desarrollo en América Latina: entre la emancipación y la adaptación al capitalismo. Revista Española de Desarrollo y Cooperación, 2017, (39), 9-24. GRISUL. Pacha defendiendo la tierra. Extractivismo, conflictos y alternativas en América Latina y Caribe, UNIRIO: Rio de Janeiro, 2018. Disponible en: http://www.grisulunirio.com/ [Consultado el 12 de mayo de 2018].
} 
regional y global. Las metodologías más utilizadas en el campo de los estudios del desarrollo, al analizar sobre todo las prácticas institucionales y políticas de gobiernos y actores privados, tampoco facilitan la comprensión de este fenómeno. Además, en América Latina y Caribe, las luchas y resistencias diarias de estos grupos se invisibilizan por estar lejos de los centros urbanos y de decisión o por constituir formas de oposición activas al modelo de desarrollo vigente, considerado legítimo a los ojos de las élites y los poderes públicos y privados. Como consecuencia, estas luchas son objeto de noticia apenas en ocasión de grandes movilizaciones o de la muerte de algún activista.

En contraposición a este relativo "olvido" o selectividad en el estudio de las disputas sobre el desarrollo, nuestra propuesta recupera la noción de conflicto como elemento nodal de la política y pretende visibilizar las luchas y resistencias de los movimientos sociales ${ }^{4}$, teniendo en consideración sus características, pero también sus estrategias de movilización y resistencia propias. Consideramos que tanto la organización de marchas, ocupaciones o la promoción de campañas de sensibilización y legislación constituyen formas de lucha y resistencia ante el avance del extractivismo. En la misma medida, creemos que la politización de todas las esferas con una activa actuación en los ámbitos público o privado, así como la formulación de discursos y narrativas o el uso estratégico de identidades, constituyen importantes formas de participación para mujeres, campesinos, indígenas y afrodescendientes, colectivos tradicionalmente relegados en los procesos de toma de decisión de la región.

A través de una cartografía de las luchas y resistencias de los movimientos sociales en América Latina y Caribe, queremos escuchar y trasmitir sus voces, evidenciando el protagonismo de estos colectivos en los conflictos socioambientales que derivan del extractivismo a nivel regional. Nuestra investigación utiliza como fuente de información la base de datos del Environmental Justice Atlas (EJATLAS) ${ }^{5}$, plataforma que reúne 2.390 conflictos socioambientales en el periodo 1970-2018. Considerando que América Latina y Caribe es la región más letal para activistas medioambientales y opositores al extractivismo, visibilizaremos no solo las resistencias a este modelo, sino también las alternativas que emergen progresivamente y se expanden por todo el territorio. Con este fin, a partir de criterios como los impactos ambientales, de género o étnicos de estos conflictos, el desplazamiento forzado que provocan, la activa participación que en ellos desempeñan las mujeres, afrodescendientes e indígenas o el papel de las multinacionales, seleccionamos 259 conflictos socioambientales derivados del extractivismo minero en la región ${ }^{6}$.

El artículo está estructurado en tres partes. La primera discute teóricamente las resistencias sociales y alternativas al modelo de desarrollo hegemónico, surgidas a partir del fracaso de sus estrategias y de la proliferación de luchas en torno a la justicia ambiental

4 BRINGEL, B. y ECHART, E. Movimientos sociales, desarrollo y emancipación. En Sotillo, José Ángel (Dir.) Antología del Desarrollo (pp.573-670). Madrid: IUDC/La Catarata, 2015.

5 El Environmental Justice Atlas (EJATLAS) es un portal colaborativo que reúne conflictos ambientales de diversa tipologia (2.390 hasta el 27/03/2018), bajo la dirección de Joan Martínez Alier y Leah Temper y la coordinación de Daniela del Bene de la Universidad Autónoma de Barcelona y el Institute of Environmental Science and Technology (ICTA). Para más informaciones, consultar: http://ejatlas.org/

6 GRISUL. Pacha defendiendo la tierra... op.cit. En este documento pueden encontrarse diversos mapas ilustrativos de los diversos impactos de estos conflitos. 
y climática, que Martínez Alier ${ }^{7}$ denomina Ecologismo de los Pobres. El segundo apartado analiza los rasgos esenciales del extractivismo clásico y del neoextractivismo. Finalmente, la tercera parte es una cartografía de las resistencias y alternativas al extractivismo en América Latina y Caribe que busca visibilizar el papel de los movimientos sociales en las disputas sobre el sentido del desarrollo de la región. El artículo cierra con algunas consideraciones finales que nos invitan a pensar de modo alternativo las posibilidades de desarrollo.

\section{Resistencias sociales}

El desarrollo es un concepto y una estrategia históricamente cuestionada y objeto de reformulación. Tanto en el Norte como en el Sur se han puesto en evidencia sus promesas incumplidas y sus efectos no deseados sobre el medioambiente y las futuras generaciones, o sus consecuencias diferenciadas sobre territorios locales, mujeres, poblaciones indígenas y afrodescendientes. Ante los planteamientos clásicos de la teoría del crecimiento o de la modernización (formulada en los países del Norte) que definía el subdesarrollo como una fase temporal y preconizaba el desarrollo por etapas desde sociedades tradicionales a sociedades de consumo, surgieron los cuestionamientos de estas premisas desde el Sur y la denuncia de que el desarrollo era una quimera y el subdesarrollo una condición estructural, basada en la exportación de materias primas y en la reproducción de ventajas para las economías centrales. Las críticas estructuralistas, la teoría de la dependencia y de los sistemas mundo, concentraron este debate desde los años sesenta, con el protagonismo activo de intelectuales como Theotonio Dos Santos ${ }^{8}$, Ruy Mauro Marini ${ }^{9}$, Vânia Bambirra ${ }^{10}$ o Immanuel Wallerstein ${ }^{11}$. Desde la década de los setenta, emergen también con fuerza las reformulaciones del desarrollo propuestas desde enfoques neoliberales o neodesarrollistas ${ }^{12}$.

Más allá de las propuestas de reformulación y la corrección de los errores o límites del desarrollo, desde el Sur se cuestionan también las raíces etnocéntricas, capitalistas, coloniales y patriarcales de este modelo, así como su perspectiva universal y homogeneizadora que invisibiliza las diferencias y otras concepciones de bienestar ${ }^{13}$.

Sin embargo, las disputas por el desarrollo no fueron solo teóricas, sino que incluyeron numerosas prácticas y repertorios de acción en los que los movimientos sociales tuvieron y

\footnotetext{
MARTÍNEZ ALIER, Joan. O Ecologismo dos Pobres: conflitos ambientais e linguagens de valoração. São Paulo: Contexto, 2007. MARTÍNEZ ALIER, Joan. "Economía Ecológica y Justicia Ambiental", en HOETMER, Raphael; CASTRO, Miguel; DAZA, Mar; DE ECHAVE, José y RUIZ, Clara. Minería y movimientos sociales en el Perú. Instrumentos y propuestas para la defensa de la vida, el agua y los territorios. Lima: Programa Democracia y Transformación Global, CooperAcción, ACSUR Las Segovias, Entre Pueblos, 2013, pp. 81-93.

8 DOS SANTOS, Theotonio. A Teoria da Dependência. Balanço e Perspectivas, Niterói, Editora Insular, 1998.

9 MARINI, R. M. "Dialética da dependência", en SADER, Emir (Org.). Dialética da dependência: uma antologia da obra de Ruy Mauro Marini. Petrópolis: Rio de Janeiro: Buenos Aires: Vozes / Bueno Aires, CLACSO, (1973) 2000, pp. 105-165.

10 BAMBIRRA, Vânia. El capitalismo dependiente latinoamericano. México D.F., Siglo Veintiuno editores, 1974.

${ }^{11}$ WALLERSTEIN, Immanuel. Análisis de sistemas-mundo. Una introducción. Madrid: Siglo XXI Editores, 2006.

12 PAYNE, Anthony; PHILLIPS, Nicola. Desarrollo. Madrid: Alianza Editorial, 2012.

${ }^{13}$ QUIJANO, Aníbal. "¿Bien vivir? Entre el 'desarrollo' y la descolonialidad del poder", en DAZA, Mar; HOETMER, Raphael y VARGAS, Virginia.: Crisis y movimientos sociales en Nuestra América: cuerpos, territorios e imaginarios en disputa. Lima, Programa Democracia y Transformación Global, 2012, p. 125-135. ACOSTA, Alberto. "Extrativismo e neo-extrativismo. Duas faces da mesma maldição", en DILGER, Gerhard; LANG, Miriam; PEREIRA, Jorge (Org.). Descolonizar o imaginário. Debates sobre pós-extrativismo e alternativas ao desenvolvimento. São Paulo: Elefante Editora, 2017.
} 
continúan teniendo un papel central ${ }^{14}$. La oposición al neoliberalismo y a la firma de acuerdos de libre comercio, así como las protestas contra la globalización, por "otra globalización" o porque "otro mundo es posible" fueron centrales para este proceso y encontraron espacios de convergencia en encuentros regionales e internacionales, como el Foro Social Mundial, organizado a partir de 2001. Dichas protestas cuestionaban también las formas clásicas de canalización de demandas y el papel tradicional de partidos políticos y sindicatos en este proceso, proponiendo en alternativa formas de organización colectiva, autónomas, horizontales y en red, basadas en demandas comunitarias en torno al derecho a la tierra que incluían también reivindicaciones étnicas o de género. En plena implementación de reformas estructurales en América Latina, y especialmente en los noventa, periodo también conocido como la década de los pueblos indígenas, algunos de los ejemplos más representativos de este proceso fueron la emergencia del Movimiento de los Sin Tierra (MST) en Brasil, la creación del Ejército Zapatista de Liberación Nacional (EZLN) en Chiapas o la fundación de la Vía Campesina.

Desde el enfoque del Ecologismo de los Pobres ${ }^{15}$ se visibiliza este proceso, ilustrando que las críticas al desarrollo están constituidas por una pluralidad de formas de protesta y resistencia global. Estos procesos, pensando en las asimetrías de los costes del desarrollo -mayores en los países del Sur-, o en los derechos de las futuras generaciones, promueven formas de justicia intra e intergeneracional. Las protestas y resistencias surgidas en este marco ponen en evidencia la deuda ecológica de los países del Norte respecto a los del Sur y fenómenos como el racismo ambiental ${ }^{16}$, que permite denunciar las mayores desventajas y costos de la contaminación experimentados por las poblaciones negras, indígenas o campesinas. En efecto, para Martínez Alier ${ }^{17}$, siguiendo la interpretación de David Harvey ${ }^{18}$, el modelo de desarrollo vigente promueve no solo una acumulación de beneficios y capital mediante la desposesión o expropiación de los territorios, sino que genera también una acumulación por la contaminación producida que no se paga, sino que se transfiere a las poblaciones pobres o a las futuras generaciones.

En este contexto, los pobres protestan y resisten no necesariamente porque sean ecologistas, sino porque los recursos como la tierra y el agua son la condición sine qua non para su sobrevivencia. De ahí que sus luchas sean también conocidas como Ecologismo de los Pobres. Para hacer oír su voz, los movimientos sociales y las comunidades afectadas por las estrategias de desarrollo se sirven de diversas prácticas que incluyen protestas, bloqueos, ocupaciones, manifestaciones artísticas y narrativas estratégicas sobre la Pacha Mama, la defensa del agua, de los bosques o los ríos. En espacios donde sus demandas y deseos se invisibilizan por parte de estados, organizaciones internacionales y actores privados, estas

\footnotetext{
${ }^{14}$ BRINGEL, B. y ECHART, E. Movimientos sociales, desarrollo y emancipación... op.cit. BRINGEL, B. y ECHART, E. Imaginarios sobre el desarrollo... op.cit.

${ }^{15}$ MARTÍNEZ ALIER, Joan. O Ecologismo dos Pobres... op.cit. MARTÍNEZ ALIER, Joan. Economía Ecológica... op.cit.

${ }^{16}$ Este concepto defendido por autores como Joan Martínez Alier se refiere a las injusticias sociales y ambientales tales como la elevada exposición a la contaminación o la falta de acceso a recursos naturales y a derechos como el disfrute de aire limpio y agua potable que sufren las poblaciones más pobres y vulnerables.

${ }_{17}$ Ibídem.

18 HARVEY, David. El 'nuevo' imperialismo: acumulación por desposesión. Socialist Register. Buenos Aires: CLACSO, 2004.
} 
estrategias tienen impacto y se articulan con redes de solidaridad internacional y movimientos trasnacionales que luchan por la justicia ambiental y climática.

En la tradición de pensamiento de autores como Carl Schmitt, según Mouffe ${ }^{19}$, el rol del conflicto como constitutivo de lo político es una categoría central de análisis para entender el poder, el antagonismo y las luchas. En contraposición a las perspectivas de lo político como espacio de libertad y deliberación política, reconocer el carácter conflictual de la política implica visibilizar su orden construida y hegemónica, resultado de relaciones de poder, así como la existencia de discursos y prácticas contrahegemónicas plurales que buscan alterar estas relaciones desde una concepción agonística de la democracia. De esta forma, la autora sienta las bases para pensar la política democrática, de forma radical y plural, como práctica de negociación de la diferencia y no como espacio de superación de los conflictos. De forma complementaria a esta visión, diversos estudios sobre la resistencia ${ }^{20}$ han demostrado que los movimientos sociales tienen un rol protagonista y desafían al poder, a nivel discursivo y práctico, a partir de diversas modalidades y en espacios complejos de interacción.

Bajo la óptica de una geopolítica crítica, Routledge llama, por ejemplo, terrenos de resistencia a "los lugares de contestación y a la multiplicidad de relaciones entre el poder y los discursos hegemónicos y contrahegemónicos, entre las fuerzas y las relaciones de dominación, sometimiento, explotación y resistencia"21. Este enfoque permite comprender cómo los movimientos sociales desafían las concepciones de hegemonía, consentimiento y poder centradas en el Estado, bien en los espacios físicos, bien en los discursos y narrativas donde, mediante el uso de creatividad y estrategias tácticas, los movimientos dotan a sus demandas de un sinnúmero de significados, unificando contemporáneamente contestaciones ambientales, de género o étnicas. Aquí es necesario identificar las expresiones culturales específicas de cada movimiento, así como su lenguaje y formas concretas de descontento o la producción y articulación de conocimientos alternativos. No obstante, el autor considera que de forma creciente determinadas resistencias son cada vez más regionales e internacionales en relación a sus objetivos y formas de organización. Por ello, las diversas expresiones de la resistencia permiten entender concepciones mas radicales de lo político, que dan protagonismo a la centralidad de los lugares y territorios para los movimientos, así como la interacción entre luchas y procesos locales y globales.

De forma complementaria, Featherstone ${ }^{22}$, vinculando las nociones de espacio y acción política - centrales en los procesos de resistencia-, habla de una geografía de las solidaridades y de los antagonismos, fluida, abierta, internacional y en red. Esta geografía supera los límites de los estados nacionales y las estructuras clásicas de organizaciones jerárquicas tradicionales vinculadas a partidos políticos y sindicatos basadas en identidades fijas, cuyas prácticas, más allá del discurso, reproducían jerarquías geográficas entre Norte y

\footnotetext{
${ }^{19}$ MOUFFE, Chantal. En torno a lo político, Madrid: Fondo de Cultura Económica, 2007.

${ }^{20}$ ROUTLEDGE, Paul. "Critical geopolitics and terrains of resistance" Political Geography, 1996, v. 15, n 6/7, pp. 509-531. FEATHERSTONE, David. Resistance, Space and Political Identities: The Making of Counter-Global Networks. Wiley-Blackwell, United Kingdom, 2008. FORLANI, Nicolás; QUIROGA, María; BRIZZIO, Marcela. Las resistencias al extractivismo en las ciencias sociales latinoamericanas: algunas consideraciones históricas y políticas. Crítica y Resistencias. Revista de Conflictos sociales latinoamericanos, año 2, 2016, pp. 5-22.

${ }^{21}$ ROUTLEDGE, Paul. "Critical geopolitics...op.cit., p. 516.

${ }^{22}$ FEATHERSTONE, David. Resistance...op.cit., p. 45.
} 
Sur, de género o étnicas. Así, las redes de solidaridad se construyen a partir de conexiones, relaciones y articulaciones entre espacios. Además, en contraposición a las concepciones meramente prácticas de la solidaridad, el autor visibiliza las emociones, los afectos y la importancia de las ideologías para las acciones de movilización política y resistencia que constituyen las "geografías afectivas de conexión"23.

Por otro lado, analizando las luchas y resistencias contra el avance del extractivismo en América Latina, autores como Forlani, Quiroga y Brizzio ${ }^{24}$ han puesto énfasis en las diferencias que asumen los procesos de movilización y resistencia según el periodo histórico o el contexto social y económico, el tipo de gobierno en el poder y las alianzas o compromisos que los movimientos sociales construyen con estos últimos. Los autores destacan, en particular, el escenario paradójico de la última década en la región, donde el avance del modelo de desarrollo extractivista estuvo acompañado de altos niveles de gasto social que permitieron mayores inversiones en esferas como la salud y la educación, a la par que posibilitaron la reducción del hambre y la pobreza mediante programas como Bolsa Familia, en Brasil o el proyecto de Bono de Desarrollo Humano, en Ecuador. En este nuevo contexto, la efervescencia de la movilización social asumió nuevos rasgos y los repertorios de acción fueron ampliados, también como consecuencia de las mejores y más eficientes tecnologías de la información y comunicación.

Así, muchos movimientos mantienen formas de organización asamblearias en los ámbitos local y nacional, pero incluyen también nuevas y múltiples articulaciones regionales e internacionales que trascienden demandas específicas; mientras que el papel de las clases medias o de la academia militante es cada vez más central. Por otro lado, la presencia de acciones artísticas es también fundamental, así como la participación de sectores urbanos concientizados con los problemas del campo de sus países, aunque aún poco articulados con los movimientos que allí surgen y resisten. A nivel de relaciones entre movimientos sociales y gobiernos progresistas también se generaron diversas tensiones, pues muchos movimientos surgieron en paralelo a la creación de algunos partidos progresistas, como el Partido de los Trabajadores de Brasil, al tiempo que otros recibieron apoyo y financiación de estos gobiernos en estrategias que no descartaron la cooptación de algunos de sus líderes. Como corolario, se desarrollaron relaciones complejas que oscilan entre la convivencia crítica con el modelo de desarrollo vigente en nombre de la reducción de la pobreza y las desigualdades, o el rechazo frontal de sus discursos y prácticas, proponiendo nuevas estrategias de bienestar. Las resistencias de los movimientos sociales al extractivismo son ilustrativas en este sentido.

\section{Alternativas al desarrollo}

Las críticas al desarrollo que se multiplican en América Latina y Caribe, valorizan el conocimiento y prácticas de los pueblos indígenas, afrodescendientes y mujeres -tradicionalmente relegadosy permiten el cuestionamiento del desarrollo basado en el crecimiento económico como promotor de bienestar. Así, por ejemplo, desde el enfoque postdesarrollista, se ilustran no solo la oposición o el rechazo de las estrategias de desarrollo en sus diversas formulaciones, sino que se sistematizan las propuestas surgidas de las demandas, visiones y saberes de los

\footnotetext{
${ }^{23}$ Ibídem, p. 45.

${ }^{24}$ FORLANI, QUIROGA, BRIZZIO. Las resistencias... op.cit.
} 
pueblos del Sur que, en contraposición a las premisas clásicas de este modelo, valorizan el cuidado de la naturaleza o la importancia de las relaciones comunitarias y la solidaridad ${ }^{25}$.

Dichas propuestas no constituyen, con todo, meras reacciones o formas de resistencia ante la estructura promotora y los dispositivos del desarrollo que priorizan el consumo y desarticulan identidades colectivas. Antes bien, realizan una crítica radical de este modelo ${ }^{26}$. Es en este marco que surgen, por ejemplo, las propuestas de Buen vivir o Sumak Kawsay, inspiradas en las cosmovisiones de los pueblos de la región andina que incluyen nociones como la necesidad de vivir en armonía con la naturaleza y están fundamentados en valores como la solidaridad y la cooperación ${ }^{27}$.

Al igual que las resistencias, las alternativas que se formulan en la región son de diversa naturaleza y están en constante transformación. Como veremos en los próximos apartados, las alternativas son procesos de experimentación y aprendizaje colectivo que incluyen la creación de "planes de vida" y proyectos de bienestar local, la ocupación o toma de tierras, el establecimiento de áreas de protección ambiental y la reconversión de zonas amenazadas por el extractivismo en territorios con proyectos cooperativos agroecológicos y de turismo comunitario basados en alianzas, redes de comercio y servicios locales. Tales propuestas, creadas de forma autónoma o al margen de los estados, buscan alcanzar objetivos como la autosuficiencia y la soberanía alimentaria de las comunidades, están guiados por prácticas sostenibles y de solidaridad intergeneracional y, por lo general, valorizan los saberes de las mujeres y de los pueblos tradicionales de América Latina y Caribe ${ }^{28}$.

\section{Extractivismo y neoextractivismo en América Latina y Caribe}

América Latina y buena parte de los países del Caribe conquistaron su independencia mediante luchas y revoluciones durante el siglo XIX, pero el fin del gobierno de las potencias colonizadoras no garantizó la autonomía de la región. Como evidencia la teoría de la dependencia, a partir de una perspectiva histórico-estructural, desde la colonización, la inserción de las economías latinoamericanas y caribeñas en el mercado mundial se realizó de una forma subordinada en la que cabía a estos países la producción y exportación de materias primas -según necesidades externas-, y la importación y consumo de bienes industrializados producidos en los países centrales. Así, en un contexto dual y jerárquico, el subdesarrollo y la dependencia de los países periféricos no constituyen una etapa previa al desarrollo, como defendía la teoría de la modernización, sino que son la otra cara del mismo proceso, resultado

${ }^{25}$ ESCOBAR, Arturo. La invención del Tercer Mundo. Construcción y deconstrucción del desarrollo. Bogotá: Norma, 1996.

${ }^{26}$ RIST, Gilbert. El desarrollo: historia de una creencia occidental. Madrid: IUDC-La Catarata, 2002. PORTOGONÇALVES, Carlos Walter. "De saberes e de territórios: diversidade e emancipação a partir da experiência latino-americana", en CECEÑA, Ana Esther (coord.). De los saberes de la emancipación y de la dominación. Buenos Aires, CLACSO, 2008. UNCETA, Koldo. "Desarrollo, Subdesarrollo, Maldesarrollo y Postdesarrollo. Una mirada transdisciplinar sobre el debate y sus implicaciones". Carta Latinoamericana, Contribuciones en Desarrollo y Sociedad en América Latina, n0 7, 2009, pp. 1-34.

${ }^{27}$ ACOSTA, Alberto. O Bom Viver. Uma oportunidade para imaginar outros mundos. São Paulo: Editora Autonomia Literária -Elefante, 2016.

28 LANG, Miriam. "Alternativas ao desenvolvimento. Introdução", en DILGER, Gerhard; LANG, Miriam; PEREIRA, Jorge (Org.). Descolonizar o imaginário. Debates sobre pós-extrativismo e alternativas ao desenvolvimento. São Paulo: Elefante Editora, 2017, p. 42-43. PORTO-GONÇALVES, Carlos Walter. "O difícil espelho: a originalidade teórico-política do movimento dos seringueiros e a "confluência perversa" no campo ambiental no Acre", en PORTO-GONÇALVES, Carlos y HOCSMAN, Luis. Despojos y resistencias en América Latina/Abya Yala. Buenos Aires, Estudios Sociológicos, 2016. 
de los beneficios y privilegios obtenidos por los países del centro29. Por otro lado, autores como Marini ${ }^{30}$ señalaron que la dependencia también alcanza la división internacional del trabajo, haciendo que las burguesías nacionales recurran a mecanismos de superexplotación del trabajo para compensar su papel secundario en la distribución de la acumulación.

Desde finales del siglo XIX, la exportación de materias primas experimentó un crecimiento inédito en América Latina y Caribe consolidando el modelo económico primarioexportador ${ }^{31}$. En este contexto, el extractivismo representa una modalidad de acumulación que se caracteriza por una explotación intensa o en grande escala de recursos naturales, renovables o no; implica un bajo o nulo procesamiento de estos recursos y supone la producción de bienes destinados esencialmente a la exportación ${ }^{32}$. Las actividades y recursos que se incluyen dentro del extractivismo han variado a lo largo del tiempo y hoy se consideran no solo actividades de minería o de explotación de petróleo, sino también el agronegocio, la plantación industrial de árboles, la pesca predatoria, la construcción de grandes proyectos de infraestructura e incluso el turismo de lujo a grande escala ${ }^{33}$. Tales actividades se definen como extractivistas en la medida en que superan los niveles de conservación de los recursos, se orientan a la producción de bienes exportables y provocan impactos profundos y definitivos sobre las áreas y ecosistemas afectados.

Aunque el extractivismo tiene rasgos inmutables como la apropiación y explotación de la naturaleza con el objetivo de alcanzar el crecimiento económico y el desarrollo -entendido esencialmente como progreso material-, autores como Gudynas ${ }^{34}$, Riascos ${ }^{35}$ o Svampa ${ }^{36}$ distinguen el extractivismo clásico del neoextractivismo. El primero es el modelo histórico de la región que, bajo una perspectiva capitalista, ha permitido la implementación de proyectos extractivistas en procesos que incluyen gobiernos autoritarios, altos niveles de represión de las comunidades afectadas y escasos o nulos mecanismos de compensación para las mismas. En este modelo clásico, aunque la participación de los estados es significativa, las protagonistas son las empresas multinacionales que invierten en la expansión de la frontera extractiva a cambio de los beneficios económicos que estos proyectos generan.

En contraste, el neoextractivismo definiría una etapa nueva, surgida a comienzos del siglo XXI, estimulada por factores como el boom de las commodities desde el 2003, la llegada al poder de gobiernos progresistas con proyectos neodesarrollistas, especialmente

29 DOS SANTOS, Theotonio. A Teoria da Dependência. op. cit.

30 MARINI, R. M. Dialética da dependência... op.cit.

${ }^{31}$ ACOSTA, Alberto. Extrativismo e neo-extrativismo... op.cit.

32 RIASCOS, Luis. Extractivismo clásico y neoextractivismo. ¿Dos tipos de extractivismo diferentes? Revista Tendencias, v. 15, n. 2, 2014, pp. 11-29.

${ }^{3}$ SEOANE, José. Neoliberalismo y Ofensiva extractivista. Actualidad de la acumulación por despojo, desafíos de Nuestra América. Theomai 26, 2012, p. 6.

${ }^{34}$ GUDYNAS, Eduardo. "Transições ao pós-extrativismo. Sentidos, opções e âmbitos", en DILGER, Gerhard; LANG, Miriam; PEREIRA, Jorge (Org.). Descolonizar o imaginário. Debates sobre pós-extrativismo e alternativas ao desenvolvimento. São Paulo: Elefante Editora, 2017.

${ }^{35}$ RIASCOS, Luis. Extractivismo clásico... op.cit.

${ }^{36}$ SVAMPA, Maristella. "Extrativismo neo-desenvolvimentista e movimentos sociais", en DILGER, Gerhard; LANG, Miriam; PEREIRA, Jorge (Org.). Descolonizar o imaginário. Debates sobre pós-extrativismo e alternativas ao desenvolvimento. São Paulo: Elefante Editora, 2017. 
en países como Brasil, Ecuador, Bolivia, Venezuela, Argentina o Uruguay, y la disponibilidad de tecnologías cada vez más eficientes. A diferencia del modelo anterior, los principales interesados y promotores de los proyectos extractivistas en esta modalidad son los estados, que retoman su papel como promotores del desarrollo, nacionalizan sectores estratégicos y buscan recursos para financiar sus promesas de redistribución y bienestar. En nombre del "interés nacional" los gobiernos imponen la extensión de la frontera extractiva como fuente de riqueza y solución para los problemas de los países de la región. Con todo, si por un lado se reprime a las poblaciones que se oponen a los proyectos extractivos, por otro, se aumenta el gasto social y se establecen mecanismos compensadores y políticas sociales que mitigan los efectos nocivos de este modelo.

En esta nueva versión, el extractivismo creció de forma exponencial, diversificando sus actividades y asignando nuevas funciones a los países de la región. Así, por ejemplo, un país como Ecuador, tradicionalmente petrolero, amplió su frontera extractiva abriendo las puertas a la minería a gran escala, mientras que Uruguay, históricamente especializado en el sector agropecuario, optó por promover la explotación de hierro a cielo abierto ${ }^{37}$. Hoy el extractivismo opera en su versión clásica o neo en todos los países de la región y asume diversas modalidades: concentrado en el sector petrolero, en la minería o en la producción y exportación de productos agrícolas como en los casos de Venezuela Chile y Paraguay, o diversificado en múltiples sectores como sucede en Argentina, México o Bolivia. En países como Guayana Francesa el gobierno francés, mediante proyectos como "Montaña de Oro", impulsa también la industrialización de la minería, mientras que, en Estados como Trinidad y Tobago, República Dominicana, Surinam y Haití, el agronegocio se combina con la ocupación de vastos territorios para la construcción de infraestructura turística y actividades mineras ${ }^{38}$. De este modo, actualmente América Latina y Caribe es el principal territorio de explotación de minería a nivel global y su estructura exportadora concentra más de la mitad de su valor en la venta de productos primarios y manufacturas basadas en recursos naturales. Estos suponen alrededor del $14 \%$ y constituyen el mayor peso de la región en las exportaciones mundiales ${ }^{39}$.

Sin embargo, la ampliación de la frontera extractiva no puede ser vista únicamente como resultado de factores internos, de la mayor oferta de tecnologías para extraer más recursos, de la creación de más y mejores infraestructuras para transportarlos o de la vigencia de reformas neoliberales y mecanismos de atracción de la inversión privada ${ }^{40}$. Como evidencian los indicadores económicos, la extensión del extractivismo está estrechamente vinculada al aumento de la demanda global de alimentos, materia prima y energía, por parte de las economías del Norte global, pero también de forma creciente por parte de países emergentes, como China. En efecto, hasta principios de la crisis global, la importancia de las exportaciones de productos agrícolas, minerales y energía como motor de crecimiento para la región fue esencial. Esta supuso el 17,3\% a lo largo periodo $1990-2001$ y el 16,1\%, durante el periodo 2002-2008, e influenció la mayor tasa de crecimiento económico de la región

\footnotetext{
37 GUDYNAS, Eduardo. Transições ao pós-extrativismo... op.cit., p. 94.

${ }^{38}$ EJATLAS, $o p$, cit.

39 CEPAL. Panorama de la inserción internacional de América Latina y el Caribe. La región frente a las tensiones de la globalización. Santiago: CEPAL, 2016, p. 94.

${ }^{40}$ SEOANE, José. Neoliberalismo y Ofensiva extractivista... op.cit., p. 6. RIASCOS, Luis. Extractivismo clásico... op.cit.
} 
(3,7\% en el periodo 2001-2008) desde la década del setenta ${ }^{41}$.

Al margen de los beneficios macroeconómicos del extractivismo, la evidencia empírica pone en entredicho las ventajas de este modelo para promover mayores niveles de empleo o bienestar. Así, por ejemplo, mientras que en países como Chile o México la minería contribuyó a aumentar los niveles de empleo en el sector, en el periodo 1991-2014 la producción minera de Bolivia casi triplicó, pero el empleo en el sector disminuyó del 3,7\% de la tasa de empleo nacional al $1 \%{ }^{42}$. Otro ejemplo emblemático de las contradicciones del extractivismo es también Brasil, donde en 2015 tuvo lugar la ruptura de la Represa de Residuos de Fundão, en la ciudad de Mariana (Minas Gerais). El desastre provocado por la represa, perteneciente a la empresa Samarco Minería S.A., controlada por la compañía Vale S.A. y por la BHP Billiton Brasil Ltda, generó efectos permanentes como la contaminación de más de $300 \mathrm{~km}$ del Rio Doce y la liberación de 60 millones de metros cúbicos de lodo de residuos que provocaron la muerte de 19 personas, destruyeron pueblos y dejaron a más de mil habitantes de la región desabrigados y sin agua, además de haber causado la muerte de diversas especies de animales. La gravedad de la tragedia de Mariana radica en que la empresa, aún impune, es responsable por crímenes ambientales y penales, pues conocía los riesgos de la actividad de la represa y, a pesar de ello, prosiguió con sus actividades, poniendo en riesgo la vida de la población adyacente ${ }^{43}$.

Las consecuencias del extractivismo son múltiples e implican la alteración de las economías y formas tradicionales de vida de los habitantes de los territorios afectados, así como la transformación perenne de los ecosistemas que refuerzan las consecuencias de fenómenos globales como el cambio climático. De acuerdo con la Organización de las Naciones Unidas para la Alimentación y la Agricultura (FAO, 2016), en apenas 10 años (20002010), el agronegocio fue responsable por más del 70\% de la deforestación a nivel global y, desde 1990, es la principal causa de deforestación en la Amazonía. Por otro lado, solo en el periodo 2001-2013, la explotación de minas de oro provocó el derribo de aproximadamente $1.680 \mathrm{~km}^{2}$ de forestas tropicales ${ }^{44}$.

La expansión de la frontera extractiva implica también impactos directos sobre la salud, la seguridad alimentaria y la vida física de las personas. Los proyectos extractivos promovidos por los estados, por las empresas multinacionales, por acuerdos entre estos actores o mediante la participación de grupos armados privados y redes del crimen organizado implican la conquista y ocupación de grandes superficies ${ }^{45}$. Estos procesos tienen lugar mediante acuerdos y compras fraudulentas, así como a través de procesos de desalojo y expulsión de

${ }^{41}$ CEPAL (Comisión Económica para América Latina). Estudio Económico de América Latina y Caribe. La dinámica del ciclo económico actual y los desafíos de política para dinamizar la inversión y el crecimiento. Santiago: CEPAL, 2017a.

42 HEINRICH BÖLL STIFTUNG. Hechos y cifras sobre el extractivismo en América Latina. HBS, 2014.

${ }^{43}$ COMITÉ DE ESPECIALISTAS PARA EL ANÁLISIS DE LA RUPTURA DE LA REPRESA DE RESIDUOS DE FUNDÃO. Informe sobre las Causas Inmediatas de la Ruptura de la Represa de Fundão. Disponible en: http://fundaoinvestigation. com/wp-content/uplo-ads/general/PR/pt/FinalReport.pdf [Consultado el 10 de mayo de 2018]. MINISTERIO PÚBLICO FEDERAL. Denuncia presentada ante la sección judicial del Estado de Minas Gerais. Disponible en: http://www.mpf.mp.br/mg/sala-de--imprensa/docs/denuncia-samarco. [Consultado el 10 de mayo de 2018].

44 ÁLVAREZ, Nora; MITCHELL, Thomas. Global demand for gold is another threat for tropical forests. Environmental Research Letters, 2015, v. 10, ${ }^{\circ} 1,1-10$.

${ }^{45}$ GUDYNAS, Eduardo. Transições ao pós-extrativismo... op.cit. 
los habitantes locales que incluyen diversas violaciones de sus derechos humanos y provocan el desplazamiento forzado de numerosas familias ${ }^{46}$.

América Latina y Caribe constituyen hoy la región más desigual del mundo y la que posee la mayor concentración de riqueza, tierra e ingreso. Así, a pesar de los avances sociales propiciados por los gobiernos progresistas en la última década, el índice de Gini de la región continúa siendo elevado (es de 0,467 ), mientras que el $10 \%$ más rico posee un ingreso equivalente al del $60 \%$ de los habitantes de la región ${ }^{47}$. Al promover mayores niveles de concentración de la tierra y la riqueza en pocas manos, el extractivismo profundiza estos rasgos. Las consecuencias de este modelo son especialmente evidentes sobre las poblaciones rurales directamente afectadas por los proyectos extractivos, pero impactan de forma específica a los habitantes de comunidades tradicionales, indígenas, afrodescendientes y mujeres. Esto es resultado de factores como el centralismo, el colonialismo interno ${ }^{48}$ y el sistema racista y patriarcal ${ }^{49}$ que caracterizan históricamente a los países de la región. Así, por ejemplo, una de cada tres hectáreas que se entregan en la región con fines de exploración minera, petrolera, agroindustrial o forestal, pertenece a los pueblos indígenas ${ }^{50}$.

En su versión clásica o neo, el avance del extractivismo, coexistente con el panorama de alta concentración del ingreso, la riqueza y la tierra, provoca tensiones, oposición y numerosos conflictos socioambientales que se mantienen a lo largo de décadas ${ }^{51}$. Según el Fondo de Desarrollo para las Naciones Unidas (PNUD), América Latina y Caribe es una región con una conflictividad intensa en la que los conflictos socioambientales ${ }^{52}$ representan el $63 \%$ de la totalidad de conflictos sociales. En este marco, para autores como Hoetmer ${ }^{53}$ es posible distinguir, por ejemplo, entre conflictos de convivencia y de modos alternativos de ver el mundo. En los primeros las poblaciones afectadas se organizan para defender sus derechos, asumiendo posturas críticas, pero sin oponerse necesariamente a las actividades extractivas; mientras que en los segundos los afectados defienden sus modos de vida y adoptan perspectivas de oposición y rechazo pleno al extractivismo, proponiendo enfoques

46 SVAMPA, Maristella. Extrativismo neo-desenvolvimentista... op.cit.

47 OXFAM. Tierra, Poder y Desigualdad em América Latina. OXFAM Internacional, 2016. CEPAL (Comisión Económica para América Latina). Panorama Social de América Latina. Santiago: CEPAL, 2017b.

48 GONZÁLEZ CASANOVA, Pablo. "Colonialismo interno (uma redefinição)", en BORON, Atilio; AMADEO, Javier; GONZÁlEZ, Sabrina. (Orgs.). A teoria marxista hoje. Problemas e perspectivas. CLACSO: Buenos Aires, 2007.

${ }^{49}$ GARGALLO, Francesca. Feminismos desde Abya Yala. Ideas y proposiciones de las mujeres de 607 pueblos en nuestra América. Ciudad de México: Editorial Corte y Confección, 2014. AGUINAGA, Margarita; LANG, Miriam; MOKRANI, Dunia; SANTILLANA, Alejandra. "Pensar a partir do feminismo. Críticas e alternativas ao desenvolvimento", en DILGER, Gerhard; LANG, Miriam; PEREIRA, Jorge (Org.). Descolonizar o imaginário. Debates sobre pós-extrativismo e alternativas ao desenvolvimento. São Paulo: Elefante Editora, 2017.

50 OXFAM. Tierra, Poder y Desigualdad... op.cit., p. 52.

51 GRISUL. Pacha: defendiendo la tierra... op.cit

52 Estos pueden ser entendidos como el resultado de la suma de dos tipologías de conflictos: los socioeconómicos o de reproducción social y los conflictos culturales. Los primeros definen a las luchas por la satisfacción de necesidades básicas, movilizaciones a favor de políticas sociales y demandas de redistribución de recursos y de la tierra. Los segundos, por el contrario, engloban cuestiones medioambientales, étnicas, ideológicas, de derechos humanos, identitarias o de género. Calderón Gutiérrez, Fernando. La protesta social en América Latina. Cuaderno de Prospectiva Política 1. Buenos Aires: Siglo XXI Editores, 2012, pp. 271-272.

53 HOETMER, Raphael. Minería, Movimientos Sociales y las disputas del futuro: claves de lectura y pistas de reflexión-acción, en HOETMER, Raphael; Miguel Castro, Mar Daza, José De Echave y Clara Ruiz. Minería y movimientos sociales en el Perú. Instrumentos y propuestas para la defensa de la vida, el agua y los territorios. Lima: Programa Democracia y Transformación Global, CooperAcción, ACSUR Las Segovias, Entre Pueblos, 2013. p. 267. 
alternativos al desarrollo que surgen desde sus necesidades y cosmovisiones.

En ambas modalidades, las luchas y diversas formas de resistencia de las comunidades afectadas han sido y están siendo severamente criminalizadas ${ }^{54}$. A este respecto, a pesar de los límites del concepto de extractivismo para dar cuenta de la complejidad de las relaciones capitalistas, de las articulaciones entre campo y ciudad y de la superexplotación implícita de la fuerza de trabajo que las actividades de extracción comportan y propician ${ }^{55}$, su adopción ha sido esencial para los movimientos sociales y las luchas que estos promueven. En efecto, una de las principales fortalezas del uso del extractivismo por parte de la literatura crítica, ha sido la de evidenciar el carácter estructural de la expansión progresiva de diversas formas de explotación predatoria de los recursos naturales, unificando las narrativas cuestionadoras, alimentando las resistencias y permitiendo la formulación de numerosas alternativas ${ }^{56}$. A seguir analizaremos las modalidades de lucha y resistencia que los movimientos críticos o anti extractivistas adquieren en América Latina y Caribe, así como algunas de las principales alternativas formuladas respecto a este modelo.

\section{Cartografía de las resistencias y alternativas al extractivismo en América Latina y Caribe}

La resistencia contra la adquisición de tierras comunales por parte de la multinacional canadiense en México, las luchas del pueblo indígena Ngöbe-Buglé contra la minería en Panamá, las movilizaciones de las comunidades afrocolombianas para defender sus territorios contra el avance de la frontera extractiva o el protagonismo de las mujeres en la defensa de sus territorios y en la construcción de redes en el marco de conflictos socioambientales en Intag y Zamora Chinchipe (Ecuador), Cajamarca y Ferreñafe (Perú), Mariana (Brasil) o en El Yoro (Honduras), son expresiones de la pluralidad de luchas y formas de resistencia de las comunidades afectadas por proyectos de extractivismo y, en los casos que aquí analizamos, específicamente por proyectos de minería ${ }^{57}$.

Los terrenos de resistencia58 incluyen marchas por el "Agua, la Dignidad y la Vida" o "Contra la Minería", ocupaciones, denuncias y campañas de visibilización (nacionales e internacionales) de su realidad, al igual que espectaculos de teatro, conciertos, elaboración de material audiovisual o constitución de redes de solidaridad y articulaciones que movilizan pasiones y discursos propios ${ }^{59}$. Algunos ejemplos de estos procesos son la ocupación de los territorios amenazados por la minería como en el caso de Intag (Ecuador); la organización comunitaria para defender los territorios en Challapata (Bolivia), Cajamarca (Perú) y Huasco (Chile); la celebración de una consulta popular en Piedras, Tolima (Colombia) para votar contra la ampliación de la frontera extractiva; la elaboración de informes e investigaciones alternativas a las de los Estados y multinacionales como en el caso de Piquiá de Baixo (Brasil); o el protagonismo femenino en el contexto del conflicto socioambiental provocado por el

\footnotetext{
${ }^{54}$ Global Witness (2017). Defensores de la tierra... op.cit. SVAMPA, Maristella. Extrativismo neo-desenvolvimentista... op.cit.

${ }^{55}$ GAGO, Verónica; MEZZADRA, Sandro. Para una crítica de las operaciones extractivas del capital. Patrón de acumulación y luchas sociales en el tiempo de la financiarización. Nueva sociedad, n² 255, 2015, p. 44.

${ }^{56}$ SEOANE, José. Neoliberalismo y Ofensiva extractivista... op.cit., p. 6.

57 GRISUL. Pacha: defendiendo la tierra... op.cit.

${ }^{58}$ ROUTLEDGE, Paul. "Critical geopolitics... op.cit.

${ }^{59}$ FEATHERSTONE, David. Resistance... op.cit.
} 
proyecto Aratirí en Uruguay, visibilizado en el Documental "Otras voces por la tierra"60. En este escenario, que combina reivindicaciones agrarias, étnicas, de clase y género, es esencial el papel que desempeñan organizaciones como la Confederación de Nacionalidades Indígenas del Ecuador (CONAIE), fundamental en la articulación de luchas anti minería en Ecuador, o la Mesa Nacional contra la minería en el Salvador que propició, en 2017, la aprobación de una ley que prohíbe la minería metálica en el país. Del mismo modo, es crucial entender el papel que juegan articulaciones como la "Red Nacional en Defensa de la Madre Tierra" en Bolivia, para comprender los lazos de solidaridad "glocales" (es decir entre luchas locales y globales) de los procesos de resistencia críticos con el extractivismo o abiertamente contrarios a su avance.

Los impactos nocivos del extractivismo sobre el medioambiente y los recursos esenciales para la supervivencia de las comunidades afectadas, así como los propósitos de sus luchas y múltiples formas de resistencia en articulación con redes de activismo internacional, hacen de estas acciones formas de expresión del Ecologismo de los Pobres, es decir, ejemplos tangibles de la lucha por la justicia ambiental y climática ${ }^{61}$ y por una distribución más igualitaria de los costes y beneficios del desarrollo.

Como mencionábamos en el apartado anterior, la expansión del extractivismo tiene costes superiores sobre la vida de las mujeres y de los pueblos indígenas y afrodescendientes de América Latina y Caribe. Esto es resultado tanto de las características estructurales de la región, como del racismo ambiental que castiga a algunas poblaciones más que a otras con los efectos de un desarrollo basado en la explotación de recursos y el crecimiento económico sin límites. Las disputas por las tierras y los recursos naturales implícitas al extractivismo (en su versión clásica o neo), afectan especialmente a estas poblaciones favoreciendo, por ejemplo, fenómenos como el aumento de la violencia de género, la prostitución o el aumento de la carga de trabajo para las mujeres asociadas a los proyectos extractivistas ${ }^{62}$. De ahí que su participación en primera línea sea visible en tareas que van desde la organización de manifestaciones, el cuidado de los heridos por las protestas o la preparación de alimentos durante las mismas. Como ejemplos pueden servir los casos de Coro Coro y Achachucani Challapata (Bolívia), Panantza (Ecuador), Pacific Rim El Dorado (El Salvador) o Conga (Perú). Con todo, en los conflictos socioambientales, la combinación de formas de exclusión y opresión también es frecuente, afectando de forma más pronunciada a las mujeres si estas son indígenas o afrodescendientes.

Por otro lado, los pueblos indígenas y afrodescendientes enfrentan diversos desafíos que amenazan sus derechos colectivos de propiedad, así como sus identidades y formas de ver y entender el mundo. Su resistencia histórica adquiere también reivindicaciones étnicas y de derecho a existir más allá de la teórica homogeneidad proclamada por la mayoría de los

\footnotetext{
60 Disponible en https://www.youtube.com/wat-ch?v=HzjNFaiHjP8 [Consultado el 2 de febrero de 2018].

61 MARTÍNEZ ALIER, Joan. O Ecologismo dos Pobres... op.cit. MARTíneZ ALIER, Joan. Economía Ecológica... op.cit.

62 SOLANO ORTÍZ, Lina. "Mujer, violencia e industria minera", 2015. Disponible en: http://redulam.org/guatemala/ mujer-violencia-e-industria-minera/ [Consultado el 5 de mayo de 2018]. Fondo Acción Urgente América Latina y el Caribe (FAU). Extractivismo en América Latina. Impacto en la vida de las mujeres y propuestas de defensa del territorio. Bogotá: FAU, 2017.
} 
estados nacionales de la región. Así, por ejemplo, la lucha del Pueblo Saramaka en el Estado de Suriname, además de reivindicar los territorios ancestrales de los pueblos aglutinados bajo la identidad de maroons, constituye una batalla por el derecho a existir y a entender el progreso de una manera alternativa al modelo de desarrollo hegemónico. En la misma medida, las organizaciones de la comunidad Diaguita Huascoaltinos, afectadas por el conflicto binacional minero de Pascua Lima entre Chile y Argentina, reclamaban no apenas el abandono de sus territorios ancestrales por parte de la multinacional canadiense Barrick Gold, sino también el derecho "a vivir en paz" y en armonía de acuerdo a su cosmovisión.

A pesar de la riqueza de sus expresiones o del carácter pacífico de la mayoría de las formas de resistencia en los procesos aquí descritos, la acción colectiva de los movimientos sociales y comunidades afectadas enfrenta estigmas y altas dosis de violencia. La criminalización de las protestas y de la resistencia incluye diversos intentos de silenciamiento de voces críticas $u$ opositoras y heterogéneas violaciones de derechos humanos ${ }^{63}$. De acuerdo con Global Witness ${ }^{64}$, América Latina y Caribe es la región más peligrosa para líderes y defensores del medio ambiente. Solo en 2017 de los 197 ambientalistas asesinados en el mundo entero, 116 murieron en la región y más de la mitad (60\%) están relacionados de forma directa con actividades extractivistas o de minería. No obstante, estas cifras no dan cuenta de la totalidad del fenómeno, pues muchas personas no denuncian por miedo, amenazas y por el clima de impunidad vigente en muchos países que no permite la resolución de los problemas. Además, en diversos países, el actor persecutor es el estado que impulsa los proyectos extractivos, colabora abiertamente con las empresas multinacionales que los promueven o permanece indiferente a las violaciones de derechos humanos perpetradas por grupos paramilitares vinculados a corporaciones o a redes del crimen organizado. En este contexto, ir a la policía o denunciar las violaciones de derechos humanos no pasan de ser acciones simbólicas y, en la mayoría de los casos, ineficaces e incluso riesgosas. Por si fuera poco, en países como Perú, debido a los bajos salarios que percibe la policía, sus miembros tienen la posibilidad de trabajar en sus horas libres para las empresas multinacionales, unificando la opresión del Estado y del capital. En proyectos mineros como Conga y Yanacocha el resultado de esta participación ha sido letal, con diversas detenciones arbitrarias, heridos y muertes.

Como puede apreciarse en el siguiente mapa, dentro de la región, América del Sur -con Brasil, Colombia y Perú a la cabeza- es la zona más peligrosa, pero México y los países centroamericanos están cada vez más afectados. En este escenario se registran múltiples formas de violencia, ya identificadas por Galtung ${ }^{65}$ en su clásica definición del triángulo de la violencia: estructural, cultural y directa. Dichas tipologías se combinan y retroalimentan entre sí en diferentes tiempos y sirven para legitimar los ataques físicos con imaginarios sobre, por ejemplo, racionalidad y superioridad racial o culpando a las víctimas con acusaciones de agresión. Estas diversas formas de violencia, así como la estigmatización contra los líderes de movimientos sociales y defensores de la tierra incluyen amenazas contra ellas/os y sus familias, detenciones arbitrarias, causas judiciales, desalojos y desplazamiento forzado y,

\footnotetext{
${ }^{63} \mathrm{CIDH}$ (Comisión Interamericana de Derechos Humanos). Pueblos Indígenas, comunidades afrodescendientes y recursos naturales. Protección de Derechos Humanos en el contexto de actividades de extracción, explotación y desarrollo, 2015. Washington: $\mathrm{CIDH}$.

64 Global Witness (2017). Defensores de la tierra... op.cit.

${ }^{65}$ GALTUNG, Johan. Violencia cultural. Documentos de Trabajo Gernika Gogoratuz 14, 2003.
} 
muchas veces, su asesinato. La violencia adquiere características específicas en los casos de mujeres y comunidades tradicionales, donde se agrega la violencia sexual y el uso de violaciones colectivas como forma de castigo o represalia contra las acciones promovidas por los movimientos. Todas estas acciones son antecedidas por campañas de deslegitimación y criminalización de la resistencia, que acusan a sus líderes de no querer el progreso en sus territorios o de atentar contra los intereses y la seguridad nacional, definiendo sus movilizaciones como formas de terrorismo y sabotaje. 
Mapa 1. Criminalización de las luchas sociales contra la minería

\section{CRIMINALIZACIÓN DE LAS LUCHAS SOCIALES CONTRA LA MINERÍA}

Conflictos que provocaron la criminalización de las luchas y resistencias, por local*

\section{Resistencia a la adquisición de tierras por la canadiense MagSilver Buenaventura, Chihuahua-México}

En el conflicto, dos activistas fueron asesinados defendiendo un rio local de una explotación ilegal de la empresa El Cascabel, subsidiaria de MagSilver.

Cotui contra el megaproyecto de Cotui, Sánchez Ramírez-Rep. Dominicana

El megaproyecto causa intensas protestas en la región, con respuestas violentas del gobierno, que han provocado diversos heridos y el encarcelamiento de líderes y manifestantes.

Proyecto Fenix de explotación de níquel El Estor, Izabal-Guatemala

La represión de las protestas en este conflicto llevó al asesinato de Adolfo Ich en una disputa por la tierra por parte de guardias de seguridad del proyecto minero.

Tolupanes contra la minería de antimonio Norte de Honduras, El Yoro-Hondura

La oposición de los indígenas Tolupanes contra los proyectos de minería y deforestación ha generado una fuerte represión, con el encarcelamiento y el asesinato de diversos líderes.

Ngöbe-Buglé contra la minería Provincia Ngöbe-Buglé-Panamá

Los indígenas Ngöbe-Buglé han sido víctimas de represión, incluyendo heridos y muertos durante las manifestaciones por la defensa de su territorio.

Protestas contra el proyecto Mirador de la empresa Ecuacorriente Zamora Chinchipe-Ecuador

El pueblo indígena Shuar, que exige ser consultado sobre el megaproyecto, así como otros opositores al proyecto, han sido duramente reprimidos durante las protestas.
Indígenas Wayuú del Sucuy contra la explotación de carbó Mara, Zulia-Venezuela

Las disputas por el territorio aumentaron la violencia contra los Wayuu, con una fuerte

criminalización de sus acciones.

El Comité de Derechos Humanos de la Guajira denunció la represión el enajira denunció la represión, el de decenas de líderes comunitarios.

Consulta Popular sobre Minería Piedras, Tolima - Colombia

Se realizaró una consulta popular en la que se rechazaro masivamente a minería, pero el Gobierno condideró el referéndum ilegal. La militarización y la violencia contra las luchas sociales,
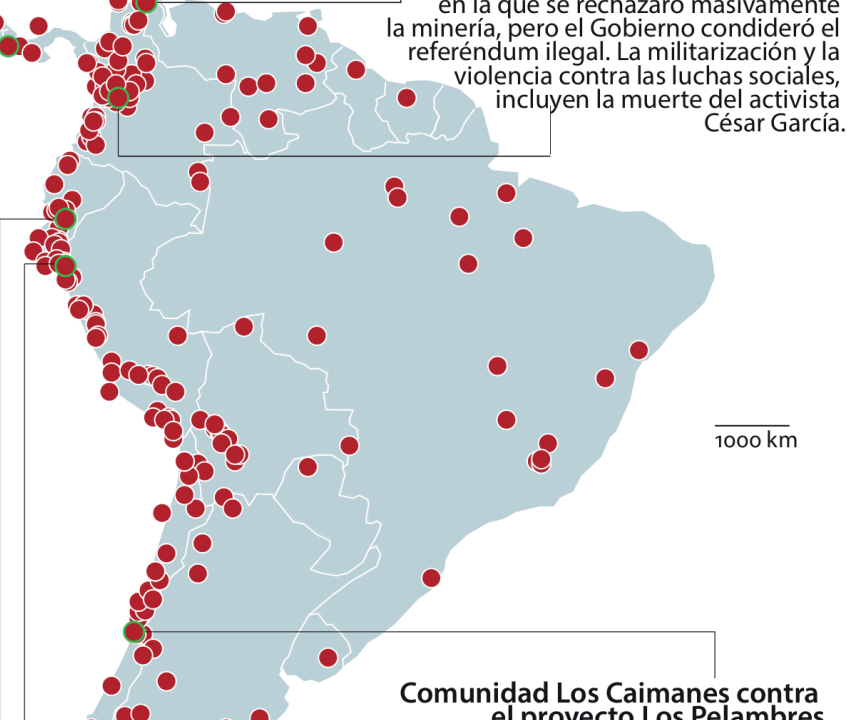

Salamanca, Coquimbo-Chile

Una acción judicial de la comunidad consiguió parar las actividades de minería por los altos niveles de contaminación, pero la empresa retomó los trabajos. Durante las manifestaciones por el respeto de la decisión judicial hubo heridos y más de 30 prisiones.

\section{Represión de la oposición al proyecto de explotación de oro y cobre
Cajamarca y Celendín-Perú}

El proyecto afecta indirectamente a 16 mil hectáreas La comunidad local, que clama por una consulta popular sobre el proyecto y sobre la participación en el lucro de la explotación, ha sufrido una fuerte represión policial con diversos prisioneros, heridos y muertos.

Fuente: Elaboración propia con base en el Environmental Justice Atlas, 2018.

Fuente: Adaptado de GRISUL. Pacha: defendiendo la tierra. Extractivismo, conflictos y alternativas en América Latina y Caribe, UNIRIO: Rio de Janeiro, 2018. 
Además de reivindicar el fin de la minería o el establecimiento de límites a la expansión del extractivismo, el uso estratégico de discursos como la defensa de la Madre Tierra, los bosques o el agua, fomenta las luchas y contribuye a generar redes de solidaridad internacional entorno a pasiones y sentimientos compartidos por movimientos sociales y comunidades afectadas en otros países y regiones. Frente a la criminalización de la protesta y de la resistencia, estas narrativas dotadas de legitimidad constituyen también formas de blindaje por parte de estos movimientos antes las denuncias de terrorismo y sabotaje y suman adhesiones tanto de organizaciones de la sociedad civil como de organismos internacionales en defensa del medioambiente. Sin embargo, más allá de expresar demandas concretas, la resistencia ante el extractivismo, en forma de convivencia crítica o abierta oposición ${ }^{66}$, cuestiona el eje central del desarrollo hegemónico: la explotación predatoria de los recursos naturales en busca del crecimiento económico y de la promoción de progreso. Los movimientos no solo critican el fracaso de este modelo a la hora de garantizar condiciones dignas de vida, sino también la herencia de muerte y destrucción que deja a su llegada a los territorios. También ponen en entredicho la universalidad del deseo de consumo, implícito al modelo de desarrollo occidental, así como la homogeneidad de visiones y formas de entender el mundo que este propicia.

Frente a los impactos nocivos del extractivismo surgen entonces múltiples propuestas, flexibles, experimentales y en constante transformación ${ }^{67}$. Estas pueden derivar 0 no en modelos alternativos de desarrollo, dependiendo de la radicalidad de las luchas o de las premisas que alimenten sus movilizaciones. Así, por ejemplo, existen propuestas que buscan promover prácticas más sustentables por parte de los proyectos extractivistas o aumentar el nivel de participación de las comunidades afectadas en la toma de decisiones que les afectan de forma directa, así como mejores niveles de redistribución de los lucros del extractivismo, reclamando más servicios sociales y trabajo a cambio de la permisión de estas actividades en sus territorios. Algunas de las propuestas que se ubican en esta línea están representadas en el siguiente mapa por la creación del Parque Nacional Gandarela (Brasil) que incluye formas de turismo comunitario en oposición a un proyecto de minería preexistente en la región; la creación de legislación de protección ambiental y la generación de redes de turismo alternativo en Sierra de la Ventana (Argentina) y Loma Miranda (República Dominicana) para evitar la explotación minera de la zona; o la suspensión o prohibición de la firma de contratos mineros a favor de las formas tradicionales de vida de la población, como en los casos ilustrados de Costa Rica y Panamá.

\footnotetext{
${ }^{66}$ HOETMER, Raphael. Minería, Movimientos Sociales... op.cit., p. 267.
}

${ }^{67}$ SVAMPA, Maristella. Extrativismo neo-desenvolvimentista... op.cit. 


\title{
Mapa 2. Más allá del extractivismo: activismo y construcción de alternativas
}

\section{MÁS ALLÁ DEL EXTRACTIVISMO: ACTIVISMO Y CONSTRUCCIÓN DE ALTERNATIVAS}

\section{Conflictos que derivaron en propuestas alternativas, por local*}



Desarrollo local sostenible contra la mina de oro Meridian

Esquel, Chubut-Argentina

\begin{abstract}
La población local, con protagonismo de la Asamblea de Vecinos Autoconvocados, luchó contra el proyecto de minería hasta el referéndum de 2003 , en el que triunfó el No al proyecto, así como la creación de un plan de desarrollo local sustentable y la conservación de prácticas y formas de vida tradicionales.
\end{abstract}

Fuente: Elaboración propia con base en el Environmental Justice Atlas, 2018.

Fuente: Adaptado de GRISUL. Pacha: defendiendo la tierra. Extractivismo, conflictos y alternativas en América Latina y Caribe, UNIRIO: Rio de Janeiro, 2018. 
Por otro lado, hay también un conjunto de prácticas que cuestionan las raíces coloniales, etnocéntricas, patriarcales y antiecológicas del modelo de desarrollo extractivista, oponiéndose a cualquier forma de convivencia con este, abriendo las puertas a perspectivas alternativas, de carácter postdesarrollista ${ }^{68}$ o postextractivista ${ }^{69}$, surgidas de sus saberes y cosmovisiones. Desde las cosmovisiones de los pueblos de la región andina, una de las propuestas alternativas que ha alcanzado mayor destaque y reconocimiento internacional es la perspectiva del Sumak Kawsay o Buen Vivir. Tras la repercusión alcanzada por la propuesta y el activismo de los pueblos indígenas de la región, sus premisas se incluyeron en dos constituciones recientes de la región: la boliviana y la ecuatoriana. Al margen del cumplimiento de estos principios, su inclusión, al igual que la introducción de las nociones de interculturalidad y plurinacionalidad en sendas Cartas Magnas constituye un hito para las luchas de los pueblos indígenas de la región y sienta un predecente para las futuras luchas a favor de formas de bienestar más ecológicas, sustentables y respetuosas de las diferencias.

Como ilustra el mapa de alternativas al extractivismo, tanto en Intag (Ecuador), como en Cajamarca (Perú) o Challapata (Bolivia) la paralización de los proyectos mineros, algunos aún en disputa, ha dado lugar al mantenimiento de formas tradicionales de vida, mediante la agricultura orgánica o la ganadería de subsistencia, pero también a transformaciones e innovaciones que incluyen formas de turismo religioso, ecológico o cultural. Así, de acuerdo a lo enunciado por Forlani, Quiroga y Brizzio ${ }^{70}$ o Svampa $^{71}$, en el marco de las resistencias recientes en la región, las demandas y manifestaciones de los movimientos sociales en lucha contra el extractivismo incorporan nuevas modalidades y amplían su repertorio de acciones. No obstante, considerando las relaciones asimétricas con los estados, empresas multinacionales o agentes paramilitares, los movimientos sociales y comunidades afectadas libran luchas desiguales en las que enfrentan numerosas dificultades y múltiples formas de violencia y criminalización. Al mismo tiempo, deben hacer cuentas con el dilema que representa oponerse al avance de los proyectos de desarrollo, en contextos caracterizados por pobreza y elevados niveles de desigualdad en los que las alternativas no siempre aseguran su subsistencia.

\section{Conclusiones}

Frente al desarrollo extractivista uniformizador, el estudio de las luchas y resistencias a la minería en América Latina y Caribe es un ejemplo tangible de la riqueza y diversidad que estas movilizaciones y formas de acción asumen, así como de las heterogéneas alternativas que de ahí surgen. El rescate del conflicto como dimensión constitutiva de lo político permite visibilizar estas luchas. Los conflictos socioambientales analizados en detalle por nuestra investigación expresan el carácter complejo, multiforme y multiescalar de los procesos de resistencia, al tiempo que dan cuenta de las redes de solidaridad y antagonismo que se forman en torno a ellos. Dichos conflictos, a través de sus formas de resistencia sociopolíticas, económicas, artísticas, visuales o narrativas y simbólicas, expresan las disputas por el sentido y las prácticas de desarrollo en la región, pero también visibilizan nuevas formas de ser y participar en lo político, extendiendo sus críticas no solo al modelo de desarrollo económico,

\footnotetext{
${ }^{68}$ ESCOBAR, Arturo. La invención del Tercer Mundo... op.cit.

${ }^{69}$ GUDYNAS, Eduardo. Transições ao pós-extrativismo... op.cit.

70 FORLANI, QUIROGA, BRIZZIO. Las resistencias... op.cit.

${ }^{71}$ SVAMPA, Maristella. Extrativismo neo-desenvolvimentista... op.cit.
} 
sino también a los modos en los que los gobiernos interpretan a la democracia y a sus formas de entender y gestionar las diferencias.

Las disputas sobre el presente y el futuro del modelo de desarrollo regional evidencian los altos costes del extractivismo en términos ecológicos, con efectos especialmente visibles en el caso de mujeres y comunidades tradicionales, indígenas y afrodescendientes. En este contexto, las resistencias de estos colectivos se multiplican y articulan demandas por la tierra, el agua, los derechos de los pueblos históricamente excluidos de la región o la igualdad de género. A pesar de la legitimidad de la que aún goza el modelo de desarrollo hegemónico como promotor de "progreso y bienestar", estos conflictos y las formas de resistencia que de ellos derivan exponen la oposición cada vez más visible frente a los efectos nocivos de este modelo, así como al racismo ambiental y a los desiguales costes que produce sobre las poblaciones. En efecto, en su versión clásica, o en su ropaje neo, que incluyó políticas sociales y mecanismos compensatorios durante la década progresista de la región, el extractivismo ha demostrado ser un modelo fracasado, capaz de producir ventajas que se concentran en pocas manos y consecuencias negativas y permanentes sobre las mayorías. Frente a este panorama, la polifonía de voces, cuestionamientos y propuestas que se multiplican en la región constituyen un patrimonio común e inspiran otras luchas capaces de impedir la destrucción del planeta, entendido, según diversos movimientos, como nuestra casa común. A este respecto, el ecologismo de los pobres y los beneficios de las luchas y procesos de resistencia a favor de la justicia ambiental y climática son comunes y constituyen los mejores aliados para la construcción de modelos económica y socialmente sostenibles.

\section{Bibliografia}

ACOSTA, Alberto. "Extrativismo e neo-extrativismo. Duas faces da mesma maldição", en DILGER, Gerhard; LANG; Miriam; PEREIRA, Jorge (Org.). Descolonizar o imaginário. Debates sobre pósextrativismo e alternativas ao desenvolvimento. São Paulo: Elefante Editora, 2017.

ACOSTA, Alberto. O Bom Viver. Uma oportunidade para imaginar outros mundos. São Paulo: Editora Autonomia Literária -Elefante, 2016.

AGUINAGA, Margarita; LANG, Miriam; MOKRANI, Dunia; SANTILLANA, Alejandra. "Pensar a partir do feminismo. Críticas e alternativas ao desenvolvimento", en DILGER, Gerhard; LANG; Miriam; PEREIRA, Jorge (Org.). Descolonizar o imaginário. Debates sobre pós-extrativismo e alternativas ao desenvolvimento. São Paulo: Elefante Editora, 2017.

ÁlVAREZ, Nora; MITCHELL, Thomas. Global demand for gold is another threat for tropical forests. Environmental Research Letters, v. $10 \mathrm{n}{ }^{\circ} 1,2015$, pp. 1-10.

BAMBIRRA, Vânia. El capitalismo dependiente latinoamericano. México D.F., Siglo veintiuno editores, 1974.

BRINGEL, Breno y ECHART, Enara. Imaginarios sobre el desarrollo en América Latina: entre la emancipación y la adaptación al capitalismo. Revista Española de Desarrollo y Cooperación, nº 39, 2017, pp. 9-24.

BRINGEL, Breno y ECHART, Enara. Movimientos sociales, desarrollo y emancipación. En Sotillo, José Ángel (Dir.) Antología del Desarrollo. Madrid: IUDC/La Catarata, 2015, pp.573-670.

CALDERÓN GUTIÉRREZ, Fernando. La protesta social en América Latina. Cuaderno de Prospectiva Política 1. Buenos Aires: Siglo XXI Editores, 2012.

CEPAL (Comisión Económica para América Latina). Estudio Económico de América Latina y Caribe. La dinámica del ciclo económico actual y los desafíos de política para dinamizar la inversión y el crecimiento. Santiago: CEPAL, 2017a.

CEPAL. Panorama Social de América Latina. Santiago: CEPAL, 2017b.

$\mathrm{CIDH}$ (Comisión Interamericana de Derechos Humanos). Pueblos Indígenas, comunidades afrodescendientes y recursos naturales. Protección de Derechos Humanos en el contexto de actividades de extracción, explotación y desarrollo, 2015. Washington: CIDH.

COMITÉ DE ESPECIALISTAS PARA EL ANÁLISIS DE LA RUPTURA DE LA REPRESA DE RESIDUOS 
DE FUNDÃO. Informe sobre las Causas Inmediatas de la Ruptura de la Represa de Fundão. Disponible en: http://fundaoinvestigation.com/wp-content/uplo-ads/general/PR/pt/FinalReport. pdf [Consultado el 10 de mayo de 2018].

DOS SANTOS, Theotonio. A Teoria da Dependência. Balanço e Perspectivas, Niterói, Editora Insular, 1998.

ECHART, Enara. "Movimientos de mujeres y desarrollo", en CARBALLO DE LA RIVA, Marta (coord.). Género y desarrollo: cuestiones clave desde una perspectiva feminista. Madrid: IUDC-Los Libros de La Catarata, 2017, pp. 131-159.

ECHART, Enara. Movimientos sociales y Relaciones Internacionales. La irrupción de un nuevo actor. Madrid: IUDC-UCM-Los Libros de La Catarata, 2008.

EJATLAS (Environmental Justice Atlas): http://ejatlas.org/

ESCOBAR, Arturo. La invención del Tercer Mundo. Construcción y deconstrucción del desarrollo. Bogotá: Norma, 1996.

ESTEVA, Gustavo. "Desarrollo", en VIOLA, Andreu (comp.). Antropología del desarrollo. teoría y estudios etnográficos en América Latina. Barcelona: Paidós, 2000, pp. 67-101.

FAU (Fondo Acción Urgente América Latina y el Caribe). Extractivismo en América Latina. Impacto en la vida de las mujeres y propuestas de defensa del territorio. Bogotá: FAU, 2017.

FEATHERSTONE, David. Resistance, Space and Political Identities: The Making of Counter-Global Networks. Wiley-Blackwell, United Kingdom, 2008.

FORLANI, Nicolás; QUIROGA, María; BRIZZIO, Marcela. Las resistencias al extractivismo en las ciencias sociales latinoamericanas: algunas consideraciones históricas y políticas. Crítica y Resistencias. Revista de Conflictos sociales latinoamericanos, año 2, 2016, pp. 5-22.

GAGO, Verónica; MEZZADRA, Sandro. Para una crítica de las operaciones extractivas del capital. Patrón de acumulación y luchas sociales en el tiempo de la financiarización. Nueva sociedad, $n^{\circ} 255$, 2015, pp. 38-52.

GALTUNG, Johan. Violencia cultural. Documentos de Trabajo Gernika Gogoratuz 14, 2003.

GARGALLO, Francesca. Feminismos desde Abya Yala. Ideas y proposiciones de las mujeres de 607 pueblos en nuestra América. Ciudad de México: Editorial Corte y Confección, 2014.

GLOBAL WITNESS. Defensores de la tierra y del medioambiente muertos em 2017. Disponible en: https://www.globalwitness.org/en/blog/new-data-reveals-197-land-and-environmentaldefenders-murdered-2017/ [Consultado el 04 de mayo de 2018].

GONZÁLEZ CASANOVA, Pablo. "Colonialismo interno (uma redefinição)", en BORON, Atilio; AMADEO, Javier; GONZÁLEZ, Sabrina. (Orgs.). A teoria marxista hoje. Problemas e perspectivas. CLACSO: Buenos Aires, 2007.

GRISUL. Pacha: defendiendo la tierra. Extractivismo, conflictos y alternativas en América Latina y Caribe, UNIRIO: Rio de Janeiro, 2018. Disponible en: http://www.grisulunirio.com/ [Consultado el 12 de mayo de 2018].

GUDYNAS, Eduardo. "Transições ao pós-extrativismo. Sentidos, opções e âmbitos", en DILGER, Gerhard; LANG; Miriam; PEREIRA, Jorge (Org.). Descolonizar o imaginário. Debates sobre pósextrativismo e alternativas ao desenvolvimento. São Paulo: Elefante Editora, 2017.

HARVEY, David. El 'nuevo' imperialismo: acumulación por desposesión. Socialist Register. Buenos Aires: CLACSO, 2004.

HEINRICH BÖLL STIFTUNG. Hechos y cifras sobre el extractivismo en América Latina. HBS, 2014.

HOETMER, Raphael. "Minería, Movimientos Sociales y las disputas del futuro: claves de lectura y pistas de reflexión-acción", en HOETMER, Raphael; CASTRO, Miguel; DAZA, Mar; DE ECHAVE, José y RUIZ, Clara. Minería y movimientos sociales en el Perú. Instrumentos y propuestas para la defensa de la vida, el agua y los territorios. Lima: Programa Democracia y Transformación Global, CooperAcción, ACSUR Las Segovias, Entre Pueblos, 2013, pp. 265-282.

LANG, Miriam. "Alternativas ao desenvolvimento. Introdução", en DILGER, Gerhard; LANG; Miriam; PEREIRA, Jorge (Org.). Descolonizar o imaginário. Debates sobre pós-extrativismo e alternativas ao desenvolvimento. São Paulo: Elefante Editora, 2017, pp. 24-45.

MARINI, Ruy. Dialética da dependência, en SADER, Emir (Org.). Dialética da dependência: uma antologia da obra de Ruy Mauro Marini. Petrópolis: Rio de Janeiro: Buenos Aires: Vozes / Bueno Aires, CLACSO, (1973) 2000, pp. 105-165.

MARTÍNEZ ALIER, Joan. "Economía Ecológica y Justicia Ambiental", en HOETMER, Raphael; CASTRO, Miguel; DAZA, Mar; DE ECHAVE, José y RUIZ, Clara. Minería y movimientos sociales en el Perú. Instrumentos y propuestas para la defensa de la vida, el agua y los territorios. Lima: Programa Democracia y Transformación Global y CooperAcción, 2013, pp. 81-93.

MARTÍNEZ ALIER, Joan. O Ecologismo dos Pobres: conflitos ambientais e linguagens de valoração. São Paulo: Contexto, 2007.

MINISTERIO PÚBLICO FEDERAL. Denuncia presentada ante la sección judicial del Estado de Minas Gerais. Disponible en: http://www.mpf.mp.br/mg/sala-de-imprensa/docs/denuncia-samarco [Consultado el 10 de mayo de 2018]. 
MOUFFE, Chantal. En torno a lo político, Madrid: Fondo de Cultura Económica, 2007.

OIT (Organización Internacional del Trabajo). Convenio sobre Pueblos Indígenas y Tribales, n. 169. 1989. Disponible en: http://www.ilo.org/dyn/normlex/es/f?p=NORMLEXPUB:12100:0::NO: :P12100_ILO_CODE:C169 [Consultado el 10 de febrero de 2018].

OXFAM. Tierra, Poder y Desigualdad em América Latina. OXFAM Internacional, 2016.

PAYNE, Anthony; PHILLIPS, Nicola. Desarrollo. Madrid: Alianza Editorial, 2012.

PORTO-GONÇALVES, Carlos Walter. "De saberes e de territórios: diversidade e emancipação a partir da experiência latino-americana", en CECEÑA, Ana Esther (coord.). De los saberes de la emancipación y de la dominación. Buenos Aires, CLACSO, 2008.

PORTO-GONÇALVES, Carlos Walter. O difícil espelho: a originalidade teórico-política do movimento dos seringueiros e a "confluência perversa" no campo ambiental no Acre, en PORTO-GONÇALVES, Carlos y HOCSMAN, Luis. Despojos y resistencias en América Latina/Abya Yala. Buenos Aires, Estudios Sociológicos, 2016, pp. 107-140.

QUIJANO, Aníbal. "¿Bien vivir? Entre el 'desarrollo' y la descolonialidad del poder", en DAZA, Mar; HOETMER, Raphael y VARGAS, Virginia: Crisis y movimientos sociales en Nuestra América: cuerpos, territorios e imaginarios en disputa. Lima, Programa Democracia y Transformación Global, 2012, pp. 125-135.

RIASCOS, Luis. Extractivismo clásico y neoextractivismo. ¿Dos tipos de extractivismo diferentes? Revista Tendencias, v. 15, n², 2014, pp. 11-29.

RIST, Gilbert. El desarrollo: historia de una creencia occidental. Madrid: IUDC-La Catarata, 2002.

ROUTLEDGE, Paul. "Critical geopolitics and terrains of resistance" Political Geography, 1996, v. 15, n 6/7, pp. 509-531.

SEOANE, José. Neoliberalismo y Ofensiva extractivista. Actualidad de la acumulación por despojo, desafíos de Nuestra América. Theomai 26, 2012.

SOLANO ORTÍZ, Lina. "Mujer, violencia e industria minera", 2015. Disponible en: http://redulam.org/ guatemala/mujer-violencia-e-industria-minera/ [Consultado el 5 de mayo de 2018].

SVAMPA, Maristella. "Extrativismo neo-desenvolvimentista e movimentos sociais", en DILGER, Gerhard; LANG, Miriam; PEREIRA, Jorge (Org.). Descolonizar o imaginário. Debates sobre pós-extrativismo e alternativas ao desenvolvimento. São Paulo: Elefante Editora, 2017.

UNCETA, Koldo. "Desarrollo, Subdesarrollo, Maldesarrollo y Postdesarrollo. Una mirada transdisciplinar sobre el debate y sus implicaciones". Carta Latinoamericana, Contribuciones en Desarrollo y Sociedad en América Latina, no 7, 2009, pp. 1-34.

WALLERSTEIN, Immanuel. Análisis de sistemas-mundo. Una introducción. Madrid: Siglo XXI Editores, 2006. 


\section{RELACIONES INTERNACIONALES}

Revista académica cuatrimestral de publicación electrónica Grupo de Estudios de Relaciones Internacionales (GERI) Universidad Autónoma de Madrid, España

www.relacionesinternacionales.info

ISSN 1699 - 3950

ff facebook.com/RelacionesInternacionales

twitter.com/RRInternacional 